\title{
Cesarean scar pregnancy: scope for hysteroscopy
}

\author{
Nitin H. Shah, Aditi V. Joshi*, Renu Agarwal
}

Department of Obstetrics and Gynecology, Aastha Maternity and Nursing Home, Mumbai, Maharashtra, India

Received: 01 March 2019

Accepted: 08 April 2019

\section{*Correspondence:}

Dr. Aditi V. Joshi,

E-mail: avj111@gmail.com

Copyright: ( ) the author(s), publisher and licensee Medip Academy. This is an open-access article distributed under the terms of the Creative Commons Attribution Non-Commercial License, which permits unrestricted non-commercial use, distribution, and reproduction in any medium, provided the original work is properly cited.

\begin{abstract}
Scar ectopic pregnancy also known as cesarean scar pregnancy is a rare form of an extrauterine pregnancy. The blastocyst is implanted at the site of the previous cesarean scar. Most patients remain asymptomatic and are detected on routine ultrasonography imaging. The diagnosis and management of this condition is hence challenging and difficult. A timely ultrasonography in the early weeks of gestation is the key to preventing catastrophic events like uterine perforation and excessive hemorrhage. There is a wide armamentarium of treatment modalities to choose from, however each case must be individualised. Medical management has its own limitations and often patients are required to have a long-term follow-up. We present a case of a cesarean scar pregnancy managed conservatively with systemic methotrexate but subsequently requiring surgical intervention done successfully via hysteroscopy. A repeat ultrasonography done a fortnight later revealed no retained products of conception.
\end{abstract}

Keywords: Cesarean scar pregnancy, Hysteroscopy, Methotrexate

\section{INTRODUCTION}

Cesarean scar ectopic is a rare but life-threatening entity that constitutes the implantation of the pregnancy in the myometrium at the site of the previous cesarean scar. ${ }^{1}$ Almost $6 \%$ of ectopic pregnancies are cesarean scar pregnancy (CSP) and its incidence has been on a rise owing to the increased incidence of cesarean deliveries worldwide. ${ }^{2,3}$ The exact pathogenesis of this entity is yet unknown, however a proposed mechanism of its occurrence is due to a scar defect which leads to a microscopic tract as a result of poor healing. An ultrasonography with colour doppler can aid in an early diagnosis and help differentiate it from other important differential diagnosis like a cervical pregnancy or inevitable abortion. ${ }^{4}$ The aim of treatment should be to avoid massive blood loss and preserve the future fertility of the patient. Management options are numerous and should be individualized. Often it has been noted that a combination of options is more suitable than a single option. ${ }^{5}$ Recent advances in minimal access surgery has enabled the use of hysteroscopy in diagnosing as well as in treatment of these cases. Hysteroscopy provides the advantage of direct visualization and controlled operator movements for evacuation, thus avoiding devastating complications like uterine perforation.

\section{CASE REPORT}

A 35 year old, P1L1 with previous history of cesarean section done 3 years back came with chief complaints of amenorrhea since 1 month. On examination, her general condition was fair and vital parameters were stable. Cardiovascular and respiratory system examination was normal. On per abdomen examination, abdomen was soft. On per vaginum examination, uterus was bulky, anteverted, bilateral fornices were free. An early dating ultrasound showed a 5 weeks pregnancy with a possibility of a cesarean scar ectopic (Figure 1). A serum beta HCG ( $\beta$ hCG) was done, which showed a value of $6181 \mathrm{mIU} / \mathrm{ml}$. She was counselled about the available options of treatment and she wished for a conservative 
approach. Medical management with multiple dose systemic methotrexate (day 1, 3, 5, 7) with alternate day folinic acid was planned after confirming normal blood investigations.

The dose of methotrexate given was $1 \mathrm{mg} / \mathrm{kg}$ on day 1 , administered intramuscularly. Repeat beta HCG value on day 3 was 7529 and gestational sac size had increased by $2 \mathrm{~mm}$, a second dose of methotrexate was then administered (Figure 2). The third dose (day 5) of methotrexate was delayed due to elevated liver enzymes. One week later on day 12 , when repeat liver function was normal, third dose of methotrexate was given at a beta HCG value of 3095. Beta HCG values repeated subsequently were 1881 on day 22 and 78 on day 37 .

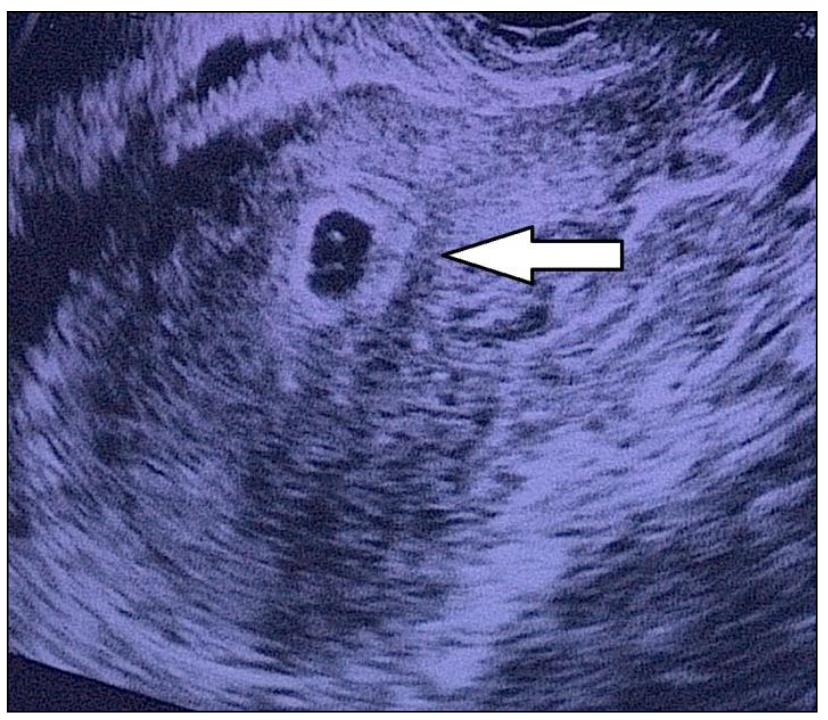

Figure 1: Ultrasonography suggestive of a scar ectopic pregnancy, arrow depicting the gestational sac.

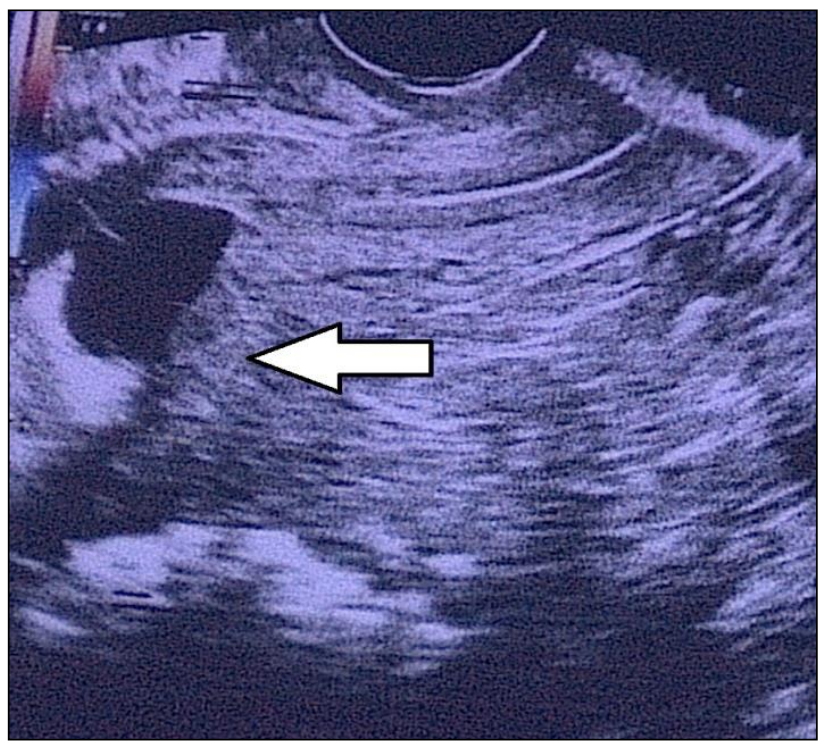

Figure 2: Ultrasonography done after 1st dose of methotrexate, showing the increased diameter of the gestational sac.

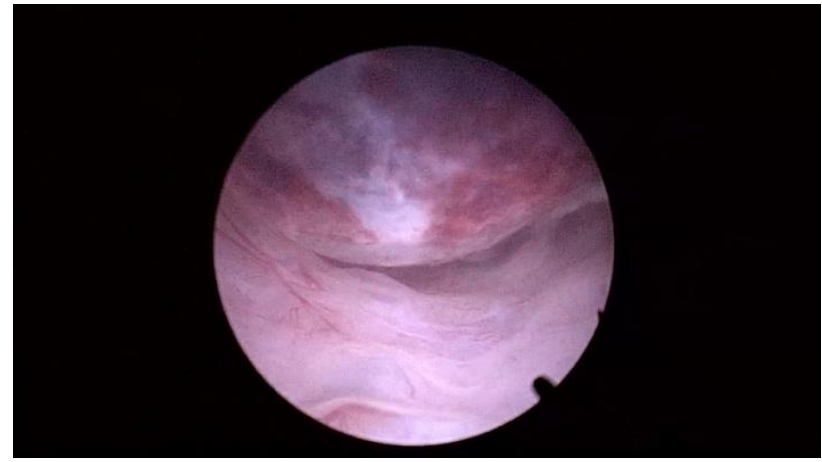

Figure 3: Illustrating the hysteroscopic view of the gestational sac.

On day 40, patient presented with bleeding per vaginum, soaking 2 pads. She was posted for a hysteroscopic removal of products of conception. On hysteroscopy, a gestational sac was noted at the site of the previous cesarean scar (Figure 3). A nick was made on the gestational sac to collapse the wall (Figure 4). The sac was then separated from the myometrium using scissors. The products were removed with the help of a $5 \mathrm{~mm}$ laparoscopic grasper by passing it by the side of the outer sheath of the hysteroscope (Figure 5, 6).

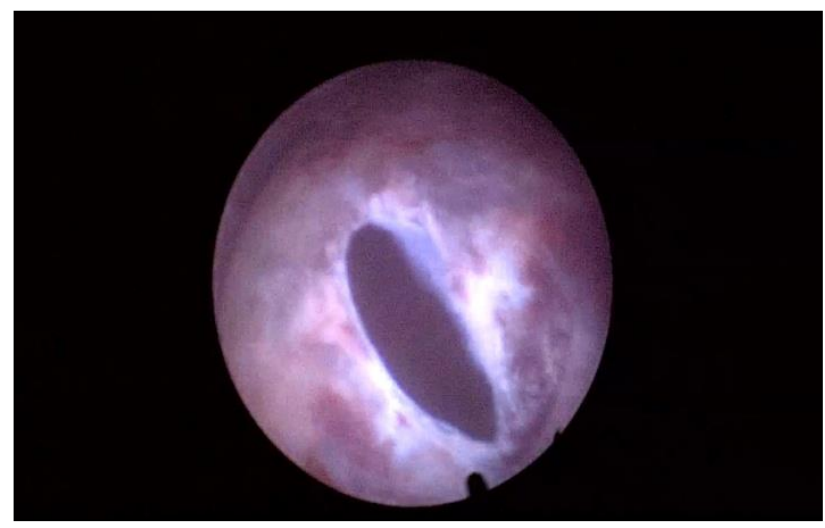

Figure 4: Illustrating the nick given on the gestational sac with scissors.

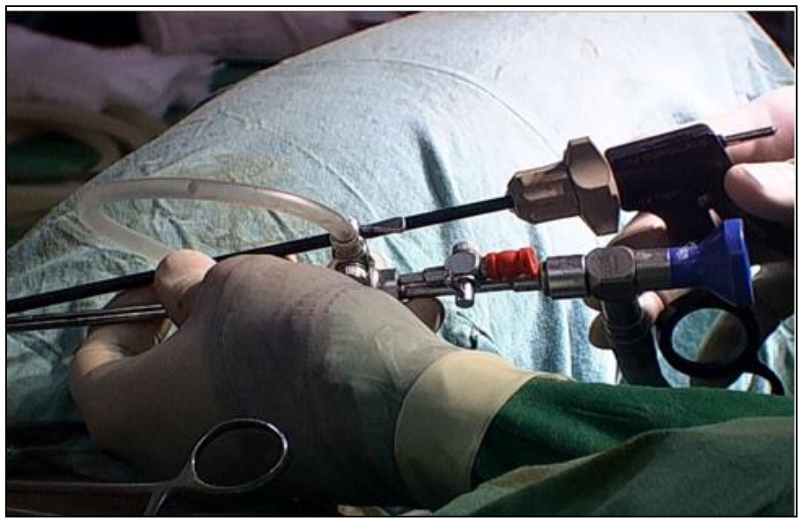

Figure 5: Image depicting passage of $5 \mathrm{~mm}$ laparoscopic grasper beside the outer sheath of hysteroscope. 


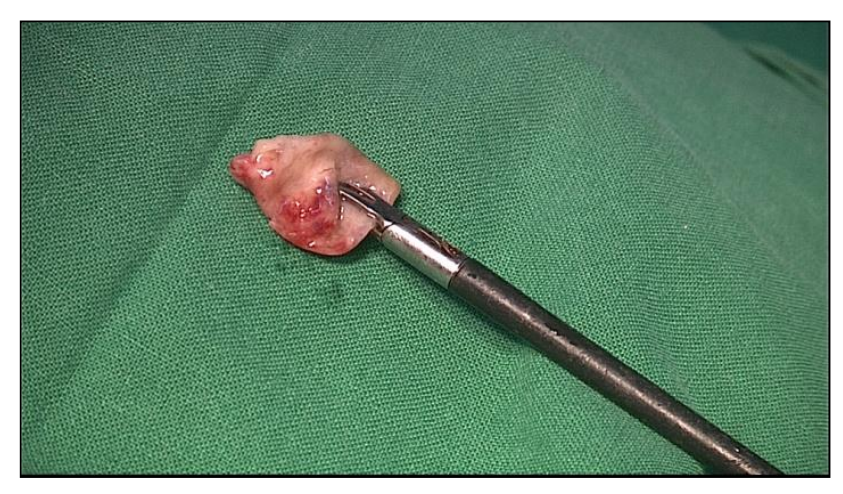

Figure 6: The products of conception removed via laparoscopic grasper.

The postoperative course was uneventful. She was discharged the same day. A repeat ultrasonography done 2 weeks later did not reveal any retained products of conception.

\section{DISCUSSION}

Cesarean scar ectopic is an uncommon clinical presentation. Currently the incidence is estimated to be around 1:1800 to 1:2200 pregnancies. ${ }^{6}$ A previous history of cesarean section is the most common risk factor for developing a cesarean scar pregnancy. Other factors include trauma due to previous curettage, manual placental evacuation, previous myomectomy or metroplasty, history of use of assisted reproductive techniques. $^{7}$

Clinical presentation is often non-specific and most cases are detected incidentally on radiological imaging. Diagnosis by transvaginal ultrasound imaging has a sensitivity of $84.6 \% .^{2}$ A radiological classification proposed by Vial et al, proposes two types of CSP. Type I comprises of the pregnancy implanted at the scar site but growing into the uterine cavity, while type II involves a pregnancy growing into the myometrium. ${ }^{8}$

Owing to the rare occurrence of this entity, there is no standard treatment option. Conservative approach involves the use of local and/or systemic methotrexate or local embryocidal agents (like intracardiac instillation of KCL) or uterine artery embolization. However, the success of these methods depends upon the gestational age and judicious patient follow-up. A greater success rate is found in patients with serum $\beta$ hCG level less than 3000 IU/L. A favourable outcome has also been noted in patients with serum $\beta$ hCG levels more than $3000 \mathrm{IU} / \mathrm{L}$ provided the patient is willing for a prolonged follow up and repeated doses of methotrexate. ${ }^{6}$ Multi dose methotrexate regimen has often shown to have a more rapid response than single dose therapy. ${ }^{9}$ Medical management has a protracted course and complete resolution of the mass can take as long as a year. Furthermore, the systemic use of the medication can lead to severe side effects in some cases. There is limited evidence in literature of a successful medical management. ${ }^{10}$ Often a combined medical and surgical method offers a better chance of resolution.

Surgical interventions include options of dilatation and curettage, laparoscopic guided suction aspiration, laparoscopic or open wedge resection, hysteroscopic evacuation or rarely hysterectomy. ${ }^{11}$ In this era of minimal access surgery, hysteroscopy and/or laparoscopy play a major role in management of these patients. They enable direct visualization of the pathology thus preventing complications associated with blind procedures like dilatation and curettage. In our case, a type I CSP, a hysteroscopic approach for evacuation of products of conception was sought for since most of the products were within the uterine cavity. The products can be separated from the underlying myometrium with the help of scissors or bipolar resectoscope. One must be vigilant about the difference in appearance of the products and normal myometrium to avoid complications like uterine perforation.

\section{CONCLUSION}

Individualizing treatment options depending upon the gestational age, $\beta \mathrm{hCG}$ levels, severity of symptoms, patient desire and compliance is the key to a successful outcome. Medical management may often be unsuccessful and requires prolonged follow up. It's always preferable to adopt a combined medical and surgical approach. Hysteroscopic modality of treatment for type I CSP offers numerous benefits like visually directed treatment, lesser operative bleeding, shorter stay and better patient compliance.

\section{Funding: No funding sources \\ Conflict of interest: None declared \\ Ethical approval: Not required}

\section{REFERENCES}

1. Herman A, Weinraub Z, Avrech O, Maymon R, RonEl R, Bukovsky Y. Follow up and outcome of isthmic pregnancy located in a previous caesarean section scar. Br J Obst Gynaecol. 1995;102(10):83941.

2. Rotas MA, Haberman S, Levgur M. Cesarean scar ectopic pregnancies: etiology, diagnosis, and management. Obst Gynecol. 2006;107(6):1373-81.

3. Lee CL, Wang CJ, Chao A, Yen CF, Soong YK. Laparoscopic management of an ectopic pregnancy in a previous caesarean section scar. Human Repro. 1999;14(5):1234-6.

4. Kirk E, Bourne T. Diagnosis of ectopic pregnancy with ultrasound. Best Pract Res Clin Obstet Gynaecol. 2009;23(4):501-8.

5. Yang XY, Yu H, Li KM, Chu YX, Zheng A. Uterine artery embolisation combined with local methotrexate for treatment of caesarean scar pregnancy. BJOG. 2010;117(8):990-6. 
6. Seow KM, Hwang JL, Tsai YL, Huang LW, Lin YH, Hsieh BC. Subsequent pregnancy outcome after conservative treatment of a previous cesarean scar pregnancy. Acta Obstet Gynecol Scand. 2004;83(12):1167-72.

7. Maymon R, Halperin R, Mendlovic S, Schneider D, Herman A. Ectopic pregnancies in a caesarean scar: review of the medical approach to an iatrogenic complication. Human Reproduct Update. 2004;10(6):515-23.

8. Vial Y, Petignat P, Hohlfeld P. Pregnancy in a cesarean scar. Ultrasound Obstet Gynecol. 2000;16(4):592-3

9. Lam PM, Lo KWK. Multiple-dose methotrexate for pregnancy in a cesarean section scar. A case report. J Reprod Med. 2002;47(4):332-4.
10. Goynumer G, Gokcen C, Senturk B. Treatment of a viable caesarean scar pregnancy with transvaginal methotrexate and potassium chloride injection. Arch Gynecol Obstet. 2009;280(5):869-72.

11. Godin PA, Bassil S, Donnez J. An ectopic pregnancy developing in a previous caesarian section scar. Fert Ster. 1997;67(2):398-400.

Cite this article as: Shah NH, Joshi AV, Agarwal R. Cesarean scar pregnancy: scope for hysteroscopy. Int J Reprod Contracept Obstet Gynecol 2019;8:213841. 